\title{
O Saresp e questões de Estatística para o nono ano do Ensino Fundamental
}

\author{
The Saresp and statistical items for the ninth year of Elementary School \\ Edmeire Aparecida Fontana ${ }^{1}$ \\ Ailton Paulo de Oliveira Júnior ${ }^{2}$
}

\section{Resumo}

A pesquisa tem por objetivo verificar se questões orientadas para o nono ano do Ensino Fundamental do Sistema de Avaliação de Rendimento Escolar do Estado de São Paulo - Saresp, abordam conteúdos estatísticos utilizando a resolução de problemas segundo o documento americano "Diretrizes para Avaliação e Instrução em Educação Estatística - GAISE”. Para a seleção das questões, houve um recorte temporal definido, pois estão disponibilizadas online nos relatórios pedagógicos de 2008 a 2018. Para a apresentação e análise das questões: descrevemos o tipo do raciocínio utilizado; analisamos segundo a resolução de problemas e a variabilidade partindo do documento GAISE; e finalmente sugerimos novas questões. Os resultados indicam que apesar de ser expresso nos relatórios pedagógicos anuais do Saresp que há a utilização da resolução de problemas na elaboração das questões não foram elaboradas considerando os princípios teóricos do documento GAISE.

Palavras-chave: Resolução de problemas, Estatística, Ensino Fundamental, Saresp.

\begin{abstract}
The research aims to verify if questions oriented to the ninth grade of the Elementary School of the São Paulo State School Performance Assessment System - Saresp, address statistical content using problem solving according to the American document "Guidelines for Assessment and Instruction in Statistical Education GAISE". For the selection of the questions, there was a definite time frame, as they are available online in the pedagogical reports from 2008 to 2018. For the presentation and analysis of the questions: we describe the type of reasoning used; we analyze by problem solving and variability from the GAISE document; and finally, we suggest new questions. The results indicate that despite being expressed in Saresp's annual pedagogical reports that problem solving is used in the elaboration of the questions, they were not elaborated considering the theoretical principles of the GAISE document.
\end{abstract}

Keywords: Problem Solving, Statistic, Elementary School, Saresp.

\section{Introdução}

O desenvolvimento da sociedade da informação, a ascensão da tecnologia e a necessidade de todas as pessoas interpretarem e analisarem informações sobre certas características ou comportamentos de populações ou fenômenos da realidade, provenientes de diferentes mídias, tornam hoje a estatística um conhecimento essencial para a participação do cidadão e a tomada de decisões.

\footnotetext{
Submetido em: 30/09/2019 - Aceito em: 28/04/2020 - Publicado em: 29/05/2020

${ }^{1}$ Mestre em Educação pela Universidade Federal do Triângulo Mineiro - UFTM. Professora da EMEF Alfredo Cesário de Oliveira, Igarapava, São Paulo, Brasil. E-mail: edmeirematematica@gmail.com.

${ }^{2}$ Doutor em Educação pela Universidade de São Paulo - USP. Professor Associado II da Universidade Federal do ABC - UFABC, Santo André, São Paulo, Brasil. E-mail: ailton.junior@ufabc.edu.br.
} 
Além disso, consideramos importante a discussão da estatística na prática, por meio da leitura, compreensão de um problema, a busca pela aplicação os elementos estatísticos que possam atender a resolução do problema.

Concordamos com Herrera (2013) quando expõe que a resolução de problemas oferece aos alunos a possibilidade de ressignificar seus conhecimentos, dando-lhes um significado.

Assim, nesta pesquisa partimos da importância de resolver problemas no processo ensino e aprendizagem (Díaz \& Poblete, 2001; Díaz-Levicoy \& Mayorga, 2014), uma vez que é uma atividade que inclui a natureza dos conteúdos que são foco do processo de ensino e aprendizagem (Chamorro \& Vecino, 2003; Pino \& Blanco, 2008), tornando-se o principal motivo de seu estudo (Pino \& Blanco, 2008).

Em relação aos estudos estatísticos, Gal (2002) afirma que são ferramentas importantes para a formação de um cidadão capacitado a resolver situações-problema que estão presentes em seu cotidiano com melhor desempenho.

Garfield e Ben-Zvi (2007) resumem os pontos de vista da pesquisa educacional sobre a aprendizagem estatística, sugerindo que o seu ensino através da resolução de problemas é importante para melhorar as habilidades dos alunos, particularmente na medida em que interagem com dados reais.

Franklin e Newborn (2006) relataram que a American Statistical Association (Associação Americana de Estatística) endossou os relatórios do Guidances for Assessment and Instruction in Statistics Education - GAISE (Diretrizes para Avaliação e Instrução no Ensino de Estatística), que defendem o aprendizado ativo de estatísticas usando dados reais e uma abordagem de solução de problemas.

Rossman, Medina e Chance (2006) e Groth (2006) consideram que usar a abordagem de resolução de problemas no ensino de estatística é de grande benefício para professores e alunos.

No Brasil, Lopes e Carvalho (2009) defendem um ensino de estatística através da problematização, permitindo aos alunos se confrontarem com problemas variados do mundo real e a partir da proposição de questões, realizem o processo de coleta, organização e representação de dados, bem como a sua interpretação e a iniciação as ideias da probabilidade.

Lopes (2008) considera importante pensar nos modos pelos quais o ensino de Estatística pode se inscrever nas práticas pedagógicas contemporâneas, mobilizado pela perspectiva da resolução de problemas. E a mesma autora, Lopes (2013), considera importante a discussão da Estatística na prática, por meio da leitura, compreensão do problema, a busca pela aplicação da ferramenta Estatística que melhor atenda a Resolução do Problema como fio condutor para uma aprendizagem significativa.

Onuchic e Allevato (2009) consideram que a aplicação de conteúdos estatísticos no ensino fundamental devem ser realizados de forma crítica, com foco na leitura e interpretação de dados, e não apenas nos cálculos e na álgebra e a metodologia de ensino escolhida para alcançar essas metas é a de resolução de problemas. O método procura gerar debates, interação e descoberta pelos alunos, mediante uma postura de estímulo de parte do professor que definem como observação participante. 
DOI: $10.20396 /$ zet.v28i0.8656898

Fini (2018) afirma que no processo de construção de raciocínio lógico matemático, incluindo a estatística, a resolução de problemas, que perpassa todos os temas da Base Nacional Comum Curricular - BNCC (Brasil, 2017), proposta curricular brasileira publicada em dezembro de 2017, constitui o eixo orientador de sua construção, pois ao enfrentar o desafio de resolver um problema, o aluno deve ser capaz de ler compreensivamente o enunciado do problema, refletir, estabelecer um plano, executá-lo, utilizar mecanismos de auto correção para comprovar a solução e, comunicar os resultados.

Além disso, Lammoglia (2013) diz que no Relatório Pedagógico de Matemática Saresp 2010 (Sistema de Avaliação de Rendimento Escolar do Estado de São Paulo) são elencados aspectos importantes a serem considerados na prática de ensino e aprendizagem, entre eles, o mais destacado é a metodologia de Resolução de Problemas, com relevância atribuída à abordagem de situações-problema das quais irão emergir conceitos e ideias matemáticos, com maiores possibilidades de o aluno aprender uma Matemática que faça sentido. Dessa forma, são expostas as etapas do ciclo da "matematização" na resolução de problemas, que envolve dois mundos, ou domínios, que se relacionam: o mundo real presente no problema como ele é proposto e o domínio matemático que envolve o problema.

Para a Secretaria da Educação do Estado de São Paulo - SEE/SP (SEE, 2009), o Saresp é uma avaliação externa do desempenho dos alunos do Ensino Fundamental e do Ensino Médio do Estado de São Paulo, para subsidiar a SEE/SP em suas tomadas de decisão quanto às políticas públicas voltadas à melhoria da educação paulista. O propósito do Saresp é verificar o rendimento escolar dos estudantes e identificar fatores nele intervenientes, fornecendo informações ao sistema de ensino, às equipes técnico-pedagógicas das Diretorias de Ensino e às escolas.

\section{A Resolução de problemas e o ensino de Estatística segundo o documento GAISE}

Segundo Lopes (2011) o documento norteador dessa pesquisa, o GAISE (Diretrizes para Avaliação e Instrução em Educação Estatística) foi aprovado em agosto de 2005 e publicado em 2007 pela Associação Americana de Estatística (ASA). O documento indica a necessidade de que o trabalho com análise de dados na Educação Básica priorize a formulação de questões que possam ser tratadas através de coleta, organização e apresentação dos dados de maneira relevante para responder a essas questões.

O documento GAISE (Franklin et al., 2007) pontua cinco aspectos considerados essenciais para o Ensino de Estatística:

(1) A resolução de problemas em estatística é um processo investigativo que envolve quatro componentes: a formulação de questões (formular uma, ou mais, perguntas que podem ser respondidas com dados), a coleta de dados (elaborar um plano apropriado para coletar dados), a análise dos dados (selecionar e utilizar métodos gráficos ou numéricos adequados para analisar os dados) e a interpretação dos resultados (relatar a interpretação de acordo com a pergunta inicial ou provocadora do problema);

(2) É preciso considerar o papel da variabilidade no processo da resolução de problemas, pois a formulação de uma questão estatística requer um entendimento sobre a diferença entre a questão que antecipa a resposta determinista e a questão que antecipa uma resposta 
DOI: $10.20396 /$ zet.v28i0.8656898

baseada na variável. A antecipação da variabilidade é a base para a compreensão de distintas questões estatísticas as quais são necessárias para a formulação de uma questão. A antecipação da variabilidade é a base para a compreensão e uma boa formulação da questão estatística;

(3) Na coleta de dados é preciso reconhecer a variabilidade nos dados. A amostragem aleatória é destinada a reduzir as diferenças entre amostra e população, e o tamanho da amostra influencia o efeito da amostragem;

(4) Na análise estatística o objetivo é o de considerar a variabilidade dos dados;

(5) $\mathrm{Na}$ interpretação dos resultados é preciso permitir a variabilidade para olhar para além dos dados. É preciso se ter clareza que interpretações estatísticas são feitas na presença de variabilidade.

Descrevemos também segundo o documento GAISE (Franklin et al., 2007) a natureza da variabilidade, destacando que existem diferentes fontes de variabilidade nos dados, ou seja:

1) Variabilidade de Medição - Medições repetidas de um mesmo indivíduo podem variar. Às vezes duas medições variam porque o dispositivo de medição produz resultados não confiáveis, como quando tentamos medir uma distância grande, com uma pequena régua. Outras vezes, os resultados sofrem alterações de variabilidade no sistema que está sendo medido;

2) Variabilidade Natural - A variabilidade é inerente a sua natureza, pois os indivíduos são diferentes. Por exemplo, quando medimos um mesmo aspecto em vários indivíduos obtemos diferenças nas medições. Embora em alguns casos as diferenças sejam devidas ao instrumento de medição, a maior parte é simplesmente devido ao fato de que os indivíduos diferem;

3) Variabilidade Induzida - Ao plantar um pacote de sementes de feijão em um determinado campo e outro bloco das mesmas sementes de feijão em outro local com um clima diferente, pode-se observar diferença no crescimento entre as sementes em uma localização diferente da outra. Isso pode ser devido a diferenças inerentes às sementes (variabilidade natural) ou a diferença observada pode ser devida ao fato de que os locais não são os mesmos;

4) Variabilidade amostral - Em uma pesquisa com eleitores, parece razoável usar a proporção de eleitores pesquisados (estatística da amostra) como uma estimativa da proporção desconhecida de todos os eleitores que apoiam um determinado candidato. Mas se uma segunda amostra do mesmo tamanho é usada, é quase certo que não seria exatamente a mesma proporção de eleitores na amostra que apoiará o candidato. $\mathrm{O}$ valor da proporção da amostra irá variar de amostra para amostra.;

5) Variabilidade de chance - Quando a seleção aleatória é usada, as diferenças entre as amostras serão devidas ao acaso. Entender essa variação de chance é o que leva à previsibilidade dos resultados. 


\section{Procedimentos Metodológicos}

O objetivo deste trabalho foi realizar uma análise das questões divulgadas do Saresp referentes aos $9^{\circ}$ ano do Ensino Fundamental, avaliações externas e de grande escala utilizada no estado de São Paulo, e verificar se as questões que abordam conteúdos estatísticos são elaboradas utilizando a resolução de problemas e qual abordagem está sendo priorizada nas questões segundo o documento GAISE.

Para a apresentação e análise de cada uma das questões das provas do Saresp referente ao nono ano do Ensino Fundamental, foi considerado o roteiro indicado a seguir:

1) Descrição do tipo do raciocínio utilizado na questão proposta pelo Saresp

Descrever o tipo de raciocínio considerado na construção das questões das provas do Saresp em análise e associar à matriz de referência que é a sinalização das estruturas básicas de conhecimento a serem construídos pelos diferentes componentes curriculares em cada nível de escolaridade, neste trabalho, conteúdos estatísticos voltados ao nono ano do Ensino Fundamental.

2) Análise da questão proposta pelo Saresp segundo a resolução de problemas e a variabilidade proposta pelo documento GAISE

A justificativa para as análises é fundamentada no documento GAISE, Franklin et al. (2007) que justifica a importância em se analisar as questões do Saresp que apresentam conteúdos estatísticos.

Desta forma, o documento enfatiza a importância da literacia estatística para desenvolver o pensamento estatístico, considerando esta literacia como a compreensão da linguagem básica da estatística e de suas ideias fundamentais. E define-se o pensamento estatístico como o tipo de pensamento utilizado quando é reconhecida a variação presente no processo, utilizam-se métodos e ferramentas estatísticas para quantificar e entender a variação, resolvem-se problemas estatísticos.

Os autores do documento destacam que o pensamento estatístico tem sido caracterizado pela necessidade de dados, pela importância dos dados de produção, pela onipresença de variabilidade e pela quantificação e explicação da variabilidade.

Alerta-se também para a importância de usar dados reais nas aulas de estatística, para que a tarefa seja autêntica e considere as questões relacionadas a como e por que os dados foram produzidos ou recolhidos; e de relacionar a análise com o contexto do problema.

3) Sugestão de nova questão a partir da questão proposta pelo Saresp

Consideramos essencial apresentar sugestões de questões, partindo do princípio que o documento GAISE considera que a Resolução de Problemas em Estatística difere da Resolução de Problemas em Matemática.

Em Franklin et al. (2007) é o foco na variabilidade dos dados que define a diferença entre a Estatística e a Matemática. Existem fontes diferentes de variabilidade nos dados e 
ainda pode-se considerar que repetidas medições de uma mesma característica do mesmo indivíduo pode variar. Portanto, a variabilidade é inerente à natureza, porque as pessoas são diferentes.

\section{Análise das questões do Saresp segundo o documento GAISE}

A seguir apresentamos análise de sete questões do Saresp de 2008 a 2018 indicadas nos relatórios pedagógicos, verificando se esta foi elaborada utilizando a resolução de problemas estatísticos e a variabilidade segundo o documento GAISE.

As provas do Saresp dos anos de 2008 a 2018 não foram disponibilizadas, e as questões analisadas foram obtidas nos Relatórios Pedagógicos referentes a cada um dos anos em que as provas foram aplicadas.

O Quadro 1 apresenta os endereços onde foram obtidas as questões dos Relatórios Pedagógicos de 2008 a 2018.

Quadro 1 - Endereços (links) onde foram obtidas as questões de Relatórios Pedagógicos do Saresp de 2008 a

\begin{tabular}{|c|c|}
\hline Relatório Pedagogico & Endereço \\
\hline 2008 & $\begin{array}{l}\text { http://saresp.fde.sp.gov.br/2008/pdf/Relatorios/2_Saresp\%202008\%20- } \\
\text { \%20Relat\%C3\%B3rio\%20Pedag\%C3\%B3gico_Matem\%C3\%A1tica.pdf }\end{array}$ \\
\hline 2009 & $\begin{array}{l}\text { http://saresp.fde.sp.gov.br/2009/ArquivosPdf/Relatorios/2_Saresp\%202009\%20- } \\
\text { \%20Relat\%C3\%B3rio\%20Pedag\%C3\%B3gico_Matem\%C3\%A1tica.pdf }\end{array}$ \\
\hline 2010 & $\begin{array}{l}\text { http://saresp.fde.sp.gov.br/2010/Pdf/Relat/Relat\%C3\%B3rio_Pedag\%C3\%B3gico } \\
\text { Matem\%C3\%A1tica_2010.pdf }\end{array}$ \\
\hline 2011 & $\begin{array}{l}\text { http://saresp.fde.sp.gov.br/2011/Pdf/Relat\%C3\%B3rio_Pedag\%C3\%B3gico_Mate } \\
\text { m\%C3\%A1tica_2011.pdf }\end{array}$ \\
\hline 2012 & http://saresp.fde.sp.gov.br/2012/ \\
\hline 2013 & $\begin{array}{l}\text { http://file.fde.sp.gov.br/saresp/saresp2013/Arquivos/SARESP\%202013_Relat\%C3 } \\
\text { \%B3rio\%20Pedag\%C3\%B3gico_Matem\%C3\%A1tica.pdf }\end{array}$ \\
\hline 2017 e 2018 & http://Saresp.vunesp.com.br/resultados9mat.html \\
\hline
\end{tabular}

Fonte: SEE.

Ressaltamos que nenhuma questão relacionada a conteúdos estatísticos foi publicada nos anos de 2014, 2015 e 2016 sendo que nos anos de 2015 e 2016 disponibilizou-se questões voltadas a resolver problemas que envolviam processos de contagem e princípio multiplicativo.

\section{Análise das questões do Saresp segundo o documento GAISE}

A seguir apresentamos análise de sete questões do Saresp verificando se foram elaboradas utilizando a resolução de problemas estatísticos e a variabilidade segundo o documento GAISE - Estrutura Curricular para o Ensino Fundamental e Médio.

Segundo SEE (2009a), Relatório Pedagógico Saresp 2008, a questão apresentada na Figura 1 pretende avaliar a seguinte habilidade: Resolver problemas que envolvam informações apresentadas em tabelas e/ou gráficos (H42). 
DOI: $10.20396 /$ zet.v28i0.8656898

Três amigos foram a uma lanchonete que apresenta o seguinte cardápio:

Pediram duas porções de batatas fritas, um hambúrguer e três refrigerantes. Dividiram igualmente a despesa, cabendo a cada um pagar, em reais
(a) $\mathrm{R} \$ 8,20$.
(b) $\mathrm{R} \$ 7,00$.
(c) $\mathrm{R} \$ 6,30$.
(d) $\mathrm{R} \$ 5,00$

Fonte: SEE (2009a, p. 98).

Figura 1 - Exemplo de item da prova do Saresp 2008 para o $9^{\circ}$ ano do Ensino Fundamental.

A questão solicita habilidades interpretativas e alfabetização estatística, visto que é necessário associar informações apresentadas na tabela. Para resolvê-la, o estudante deve calcular a despesa dos amigos e dividir o resultado por três, assinalando a alternativa " $D$ ".

Cabe aqui destacar o que é alfabetização estatística, segundo Wallman (1993), que é a habilidade para entender e avaliar criticamente resultados estatísticos que fazem parte do cotidiano, juntamente com a habilidade para apreciar as contribuições que o pensamento estatístico pode fazer em decisões públicas e privadas, profissionais e pessoais, Além disso, para Snee (1990), o pensamento estatístico é definido como processos mentais que reconhecem a variação como algo que nos rodeia e que está sempre presente em tudo o que fazemos.

O quadro 2 apresenta análise da questão apresentada na figura 1 referente à resolução de problemas segundo o documento GAISE focado nas quatro componentes do processo, bem como aos aspectos da variabilidade.

Quadro 2 - Análise da questão referente ao ano de 2008 considerando o documento GAISE.

\begin{tabular}{|c|c|}
\hline $\begin{array}{l}\text { Resolução de Problemas segundo o } \\
\text { documento GAISE }\end{array}$ & $\begin{array}{c}\text { Resolução de Problemas e a Variabilidade segundo o } \\
\text { documento GAISE }\end{array}$ \\
\hline $\begin{array}{l}\text { 1) Nessa questão, não há uma pergunta } \\
\text { estatística formulada inicialmente, visto que } \\
\text { não envolve a primeira componente "Formular } \\
\text { perguntas". A questão é um problema } \\
\text { matemático, apesar de ser necessária a leitura } \\
\text { tabular do cardápio da lanchonete. O contexto } \\
\text { está parcialmente relacionado à realidade do } \\
\text { aluno, no entanto, a questão não fornece } \\
\text { significado para a análise. } \\
\text { 2) A segunda componente "Coleta de dados", } \\
\text { também não está envolvida no processo } \\
\text { investigativo. O cardápio foi construído, } \\
\text { provavelmente pelo responsável da lanchonete. } \\
\text { 3) A terceira componente "Análise dos dados", } \\
\text { também não está envolvida no processo } \\
\text { investigativo, pois não está relacionada à } \\
\text { pergunta inicial e nem à coleta de dados. } \\
\text { 4) A quarta componente "Interpretação dos } \\
\text { resultados", também não está envolvida no } \\
\text { processo investigativo, pois não está } \\
\text { relacionada à pergunta inicial, à coleta de dados } \\
\text { e à análise dos dados. }\end{array}$ & $\begin{array}{l}\text { Como essa questão não é um problema estatístico, a } \\
\text { natureza da variabilidade não foi abordada, visto que o } \\
\text { problema é matemático e não há variação dos dados. Poderia } \\
\text { ter sido abordada a variação dos dados, caso fossem } \\
\text { apresentados os valores dos itens para mais de uma } \\
\text { lanchonete e criasse possibilidade de comparação e } \\
\text { verificação de que existem diferentes preços em diversas } \\
\text { lanchonetes para o mesmo produto. Desta forma, seria } \\
\text { abordada a variabilidade da medição. } \\
\text { Nota-se que o foco na diversidade de dados define a } \\
\text { Estatística, para além da Matemática. Refletindo sobre a } \\
\text { variabilidade dos dados, poderia ser proposta para os alunos } \\
\text { uma pesquisa em grupo pedindo o levantamento de dados de } \\
\text { um lanche e uma bebida preferida de cada aluno integrante } \\
\text { do grupo. Posteriormente, poderia ser realizada pelo grupo } \\
\text { uma coleta de dados em três lanchonetes da cidade sobre o } \\
\text { lanche e bebida preferida de cada um deles, com a } \\
\text { representação desses dados e a interpretação dos resultados } \\
\text { estaria relacionada com a questão da escolha do local que o } \\
\text { grupo poderia se reunir para lanchar, sabendo que no final a } \\
\text { conta seria igualmente rateada por eles. Assim, o contexto } \\
\text { fornece significado a variabilidade dos dados. }\end{array}$ \\
\hline
\end{tabular}

Fonte: Elaborado pelos autores. 
Assim sendo, considera-se que essa questão não foi elaborada utilizando o processo investigativo da resolução de problemas estatísticos segundo o documento GAISE, visto que para ser considerada como tal, é necessário que as quatro componentes do processo estejam envolvidas entre si e devem ser consideradas possíveis fontes de variabilidade.

Sugerimos a questão apresentada na Figura 2 que aborda conteúdos estatísticos utilizando a Resolução de Problemas segundo o GAISE.

O Quadro 3 apresenta o preço de alguns produtos vendidos em quatro lanchonetes em uma cidade do estado de São Paulo.

Quadro 3 - Produtos vendidos em quatro lanchonetes em uma cidade do estado de São Paulo.

\begin{tabular}{|c|c|c|c|c|c|c|c|c|}
\hline & $\begin{array}{l}\text { Água Mineral } \\
\text { Garrafa 500ml } \\
\text { (sem gás) }\end{array}$ & $\begin{array}{l}\text { Água Mineral } \\
\text { Garrafa 500ml } \\
\text { (com gás) }\end{array}$ & $\begin{array}{c}\text { Refrigerante } \\
\text { Lata }\end{array}$ & $\begin{array}{c}\text { Cafezinho } \\
(100 \mathrm{ml})\end{array}$ & $\begin{array}{l}\text { Pão de } \\
\text { Queijo }\end{array}$ & $\begin{array}{l}\text { Salgado } \\
\text { Simples }\end{array}$ & $\begin{array}{l}\text { Suco Natural de } \\
\text { Laranja }(300 \mathrm{ml})\end{array}$ & $\begin{array}{l}\text { Misto } \\
\text { Quente }\end{array}$ \\
\hline Lanchonete 1 & $\mathrm{R} \$ 2,00$ & $\mathrm{R} \$ 2,50$ & $\mathrm{R} \$ 3,50$ & $\mathrm{R} \$ 0,80$ & $\mathrm{R} \$ 2,00$ & $\mathrm{R} \$ 2,50$ & $\mathrm{R} \$ 3,20$ & $\mathrm{R} \$ 3,00$ \\
\hline Lanchonete 2 & $\mathrm{R} \$ 2,00$ & $\mathrm{R} \$ 2,50$ & $\mathrm{R} \$ 3,50$ & $\mathrm{R} \$ 0,90$ & $\mathrm{R} \$ 1,50$ & $\mathrm{R} \$ 2,75$ & $\mathrm{R} \$ 3,00$ & $\mathrm{R} \$ 2,75$ \\
\hline Lanchonete 3 & $\mathrm{R} \$ 2,25$ & $R \$ 2,60$ & $\mathrm{R} \$ 3,50$ & $\mathrm{R} \$ 1,00$ & $\mathrm{R} \$ 1,80$ & $\mathrm{R} \$ 3,00$ & $\mathrm{R} \$ 3,50$ & $\mathrm{R} \$ 2,75$ \\
\hline Lanchonete 4 & $\mathrm{R} \$ 2,00$ & $\mathrm{R} \$ 2,20$ & $\mathrm{R} \$ 3,00$ & $\mathrm{R} \$ 1,00$ & $\mathrm{R} \$ 1,00$ & $\mathrm{R} \$ 2,30$ & $\mathrm{R} \$ 2,50$ & $\mathrm{R} \$ 2,75$ \\
\hline
\end{tabular}

Faça a proposta de uma pesquisa solicitando o levantamento de dados de um lanche e uma bebida preferida de cada aluno integrante de sua turma. E também faça a comparação entre os preços de lanchonetes em torno da escola em que estudam, bem como a lanchonete da escola.

Fonte: Elaborado pelos autores.

Figura 2 - Sugestão de questão considerando o documento GAISE (resolução de problemas e variabilidade).

Segundo SEE (2010), Relatório Pedagógico Saresp 2009, a Questão apresentada na Figura 3 pretende avaliar a seguinte habilidade: Associar informações, apresentadas em listas e/ou tabelas simples, aos gráficos que as representam e vice-versa (H43). 


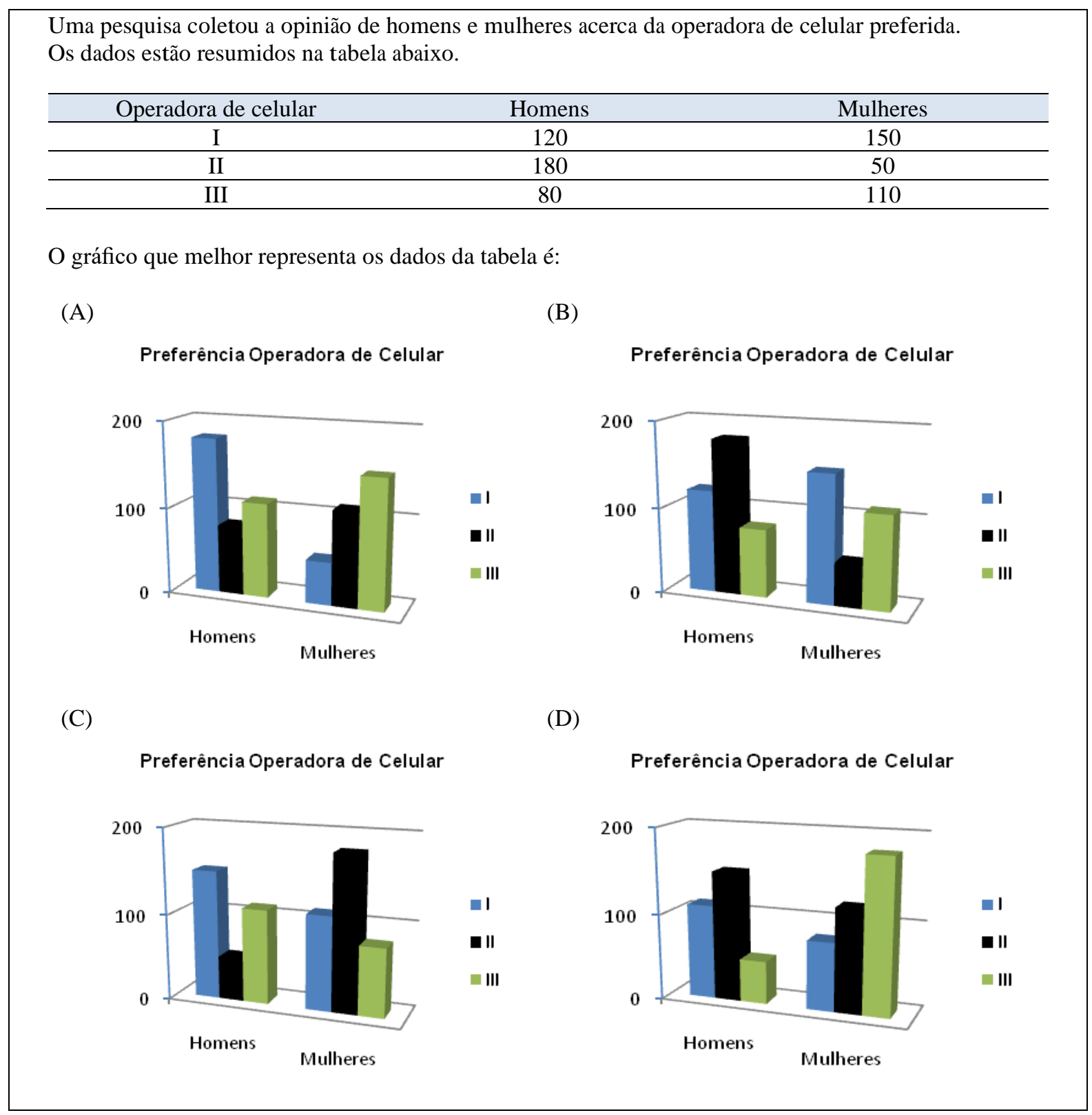

Fonte: SEE (2010, p. 147)

Figura 3 - Exemplo de item da prova do Saresp 2009 para o $9^{\circ}$ ano do Ensino Fundamental.

Essa questão solicita habilidades interpretativas e alfabetização estatística, visto que é necessário associar informações apresentadas na tabela ao gráfico que a representa corretamente, assinalando a alternativa " $\mathrm{B}$ ".

O quadro 4 apresenta análise da questão apresentada na figura 3 referente à resolução de problemas segundo o documento GAISE focado nas quatro componentes do processo, bem como aos aspectos da variabilidade. 
Quadro 4 - Análise da questão referente ao ano de 2009 considerando o documento GAISE.

\begin{tabular}{|c|c|}
\hline $\begin{array}{c}\text { Resolução de Problemas segundo o documento } \\
\text { GAISE }\end{array}$ & $\begin{array}{l}\text { Resolução de Problemas e a Variabilidade segundo } \\
\text { o documento GAISE }\end{array}$ \\
\hline $\begin{array}{l}\text { 1) A pergunta inicialmente formulada para essa } \\
\text { questão poderia ser, por exemplo, "Qual a operadora } \\
\text { de telefonia celular é preferida segundo homens e } \\
\text { mulheres?". Essa pergunta envolveria a primeira } \\
\text { componente "Formular perguntas". Observa-se que os } \\
\text { dados coletados foram realizados por outras pessoas e } \\
\text { estão parcialmente contextualizados a fato próximo da } \\
\text { realidade dos alunos. } \\
\text { 2) A segunda componente do processo envolve a } \\
\text { "Coleta de dados" que está relacionada à pergunta } \\
\text { inicial, no entanto, os dados coletados não fizeram } \\
\text { parte do processo investigativo do aluno, pois se faz } \\
\text { necessário a elaboração e a execução de um plano para } \\
\text { a coleta de dados. } \\
\text { 3) Por meio da representação tabular dos dados, } \\
\text { verifica-se que a terceira componente "Análise dos } \\
\text { dados" está envolvida na questão e vinculada a } \\
\text { pergunta formulada inicialmente, mas a coleta não foi } \\
\text { realizada pelo aluno distanciando do contexto da sua } \\
\text { realidade. Nota-se que a resolução dessa questão está } \\
\text { envolvida na terceira componente, pois a questão } \\
\text { proposta pede para o aluno assinalar a alternativa em } \\
\text { que o gráfico representa os dados da tabela. } \\
\text { 4) A quarta componente se refere à "Interpretação dos } \\
\text { resultados" que relaciona a interpretação da análise, } \\
\text { com a coleta e a interpretação da pergunta inicial, no } \\
\text { entanto a quarta componente não foi considerada nessa } \\
\text { questão. }\end{array}$ & $\begin{array}{l}\text { Nessa questão foi realizada uma pesquisa de } \\
\text { opinião acerca da operadora de celular preferida por } \\
\text { homens e mulheres, mas não foi considerada a } \\
\text { natureza da variabilidade segundo o documento } \\
\text { GAISE. Nesse caso, poderia ser abordada a } \\
\text { variabilidade natural, visto que a pesquisa é de } \\
\text { opinião, sendo inerente a natureza de homens e } \\
\text { mulheres, pois os indivíduos são diferentes e há } \\
\text { diferença entre as opiniões de homens e mulheres. } \\
\text { A pergunta formulada inicialmente "Qual a } \\
\text { operadora de telefonia celular é preferida segundo } \\
\text { homens e mulheres?" é uma pergunta estatística e a } \\
\text { busca pela resposta está baseada em coleta de dados } \\
\text { que podem variar, considerando vários fatores que } \\
\text { podem interferir na opinião sendo o gênero, classe } \\
\text { social, condições econômicas, experiência com outros } \\
\text { aparelhos, experiência com outras operadoras, entre } \\
\text { outros. A presença da variabilidade deve ser } \\
\text { considerada nas interpretações dos resultados } \\
\text { estatísticos. } \\
\text { A questão poderia ser desafiadora para o aluno } \\
\text { se a pesquisa fosse realizada por eles dentro do seu } \\
\text { contexto de realidade, como na sala de aula, na } \\
\text { escola, em casa, no bairro, entre outros. A proposta } \\
\text { seria a apresentada nesta questão, ou seja, uma } \\
\text { pesquisa de opinião sobre a telefonia de celular } \\
\text { preferida considerando a variabilidade natural no } \\
\text { processo investigativo. }\end{array}$ \\
\hline
\end{tabular}

Fonte: Elaborado pelos autores.

Sugerimos a questão apresentada na Figura 4 que aborda conteúdos estatísticos utilizando a Resolução de Problemas segundo o GAISE.

Existem no Brasil 6 grupos de operadoras de celular. A Tabela 1 a seguir apresenta estes dados, bem como o número de celulares comprados e a fração do mercado controlada por cada uma delas:

Tabela 1 - Operadora de telefonia celular, número de aparelhos vendidos e a participação no mercado brasileiro em junho de 2012.

\begin{tabular}{c|c|c}
\hline Operadora & Celulares (Milhares) & Participação no Mercado \\
\hline Vivo & 75.720 & $29,57 \%$ \\
\hline TIM & 68.874 & $26,89 \%$ \\
\hline Claro & 62.966 & $24,58 \%$ \\
\hline Oi & 47.772 & $18,65 \%$ \\
\hline CTBC & 725 & $0,28 \%$ \\
\hline Sercomtel & 74 & $0,03 \%$ \\
\hline
\end{tabular}

Fonte: Agência Nacional de Telecomunicações (Anatel) - Junho de 2012.

Elabore uma pesquisa em que você consiga determinar qual a operadora que os alunos do gênero (sexo) masculino e do gênero (sexo) feminino de sua escola utilizam e compare com os resultados segundo o gênero (sexo).

Fonte: Elaborado pelos autores.

Figura 4 - Sugestão de questão considerando o documento GAISE (resolução de problemas e 
DOI: $10.20396 /$ zet.v28i0.8656898

variabilidade).

Segundo SEE (2011), Relatório Pedagógico Saresp 2010, a Questão Aberta apresentada na Figura 5 pretende avaliar a seguinte habilidade: Resolver problemas que envolvam informações apresentadas em tabelas e/ou gráficos (H42).

Uma pirâmide alimentar indica as porções diárias que devem ser ingeridas de cada tipo de alimento. Se cada porção dos alimentos da base da pirâmide corresponde a $150 \mathrm{kcal}$ para um adulto, determine as doses diárias de calorias (mínima e máxima) provenientes desse tipo de alimento, recomendadas para um adulto.

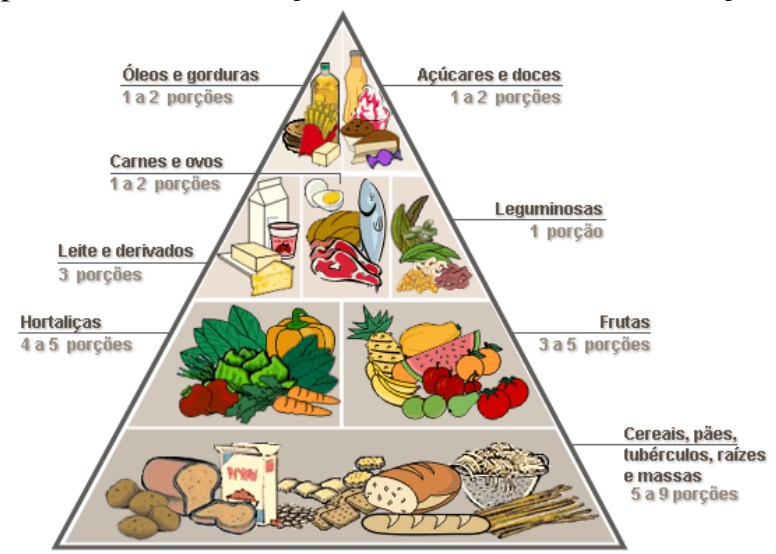

Fonte: SEE (2011, p. 98).

Figura 5 - Exemplo de questão aberta da prova do Saresp 2010 para $9^{\circ}$ ano do Ensino Fundamental.

Essa questão solicita habilidades interpretativas e alfabetização estatística, visto que é necessário associar informações apresentadas na pirâmide alimentar. Para a resolução dessa questão é necessário a interpretação da Pirâmide Alimentar, determinando as doses diárias de calorias que deve ser no mínimo 5 e no máximo de 9 dos alimentos da base da Pirâmide Alimentar, onde se encontram os cereais, pães, tubérculos, raízes e massas. No enunciado foi dado que cada porção corresponde a $150 \mathrm{kcal}$, assim sendo, a dose mínima diária proveniente destes alimentos é $5 \times 150 \mathrm{kcal}=750 \mathrm{Kcal}$ e, a dose máxima diária é de 9 × $150 \mathrm{kcal}=1350$ kcal.

O quadro 5 apresenta análise da questão apresentada na figura 5 referente à resolução de problemas segundo o documento GAISE focado nas quatro componentes do processo, bem como aos aspectos da variabilidade. 
Quadro 5 - Análise da questão referente ao ano de 2010 considerando o documento GAISE.

\begin{tabular}{|c|c|}
\hline Resc & $\begin{array}{l}\text { Resolução de Problemas e a Variabilidade } \\
\text { segundo o documento GAISE }\end{array}$ \\
\hline $\begin{array}{l}\text { 1) A pergunta inicial para essa questão poderia ser, por } \\
\text { exemplo, "Quais as porções diárias que devem ser ingeridas } \\
\text { de cada tipo de alimento que compõem a Pirâmide } \\
\text { Alimentar?". Essa pergunta formulada envolveria a primeira } \\
\text { componente do processo investigativo "Formular } \\
\text { perguntas". Observa-se que o contexto está parcialmente } \\
\text { relacionado com a realidade do aluno, pois os dados } \\
\text { coletados se referem a porções diárias de alimentos } \\
\text { recomendados para um adulto. } \\
\text { 2) Percebe-se que houve "Coleta de dados" envolvendo a } \\
\text { segunda componente da resolução, no entanto a coleta não } \\
\text { foi realizada pelos alunos o que indica limitação referente a } \\
\text { esta componente. A questão poderia ser contextualizada com } \\
\text { a realidade do aluno se as porções diárias de alimentos } \\
\text { fossem recomendadas para a faixa etária deles. } \\
\text { 3) A terceira componente "Análise dos dados" está sendo } \\
\text { considerada na questão, pois foi apresentado a Pirâmide } \\
\text { Alimentar com as porções diárias de cada tipo de alimento. } \\
\text { Nota-se que essa componente está vinculada a pergunta } \\
\text { inicial e a coleta de dados, mas o aluno não está envolvido } \\
\text { no contexto da sua realidade. } \\
\text { 4) A quarta componente "Interpretação dos resultados" está } \\
\text { relacionada à pergunta formulada, aos dados coletados e a } \\
\text { análise dos dados. A partir da interpretação dos resultados, é } \\
\text { possível determinar as doses diárias (mínima e máxima) } \\
\text { provenientes dos alimentos da base da pirâmide alimentar. }\end{array}$ & $\begin{array}{l}\text { Nessa questão foi abordada a natureza da } \\
\text { variabilidade natural dos alimentos, pois com } \\
\text { base em informações relacionadas a cada } \\
\text { alimento eles foram agrupados e organizados na } \\
\text { pirâmide alimentar, de modo que a análise e a } \\
\text { interpretação dos resultados levem em } \\
\text { consideração a variação das porções } \\
\text { recomendadas diariamente para um adulto. } \\
\text { A pergunta formulada inicialmente "Quais as } \\
\text { porções diárias que devem ser ingeridas de cada } \\
\text { tipo de alimento que compõem a Pirâmide } \\
\text { Alimentar?" é uma pergunta estatística e a busca } \\
\text { pela resposta é baseada em coleta de dados que } \\
\text { podem variar, considerando vários fatores que } \\
\text { podem interferir na opinião sendo o gênero, } \\
\text { classe social, condições econômicas, porções } \\
\text { diárias de alimentos fossem recomendadas para } \\
\text { a faixa etária deles, entre outros. A presença da } \\
\text { variabilidade deve ser considerada nas } \\
\text { interpretações dos resultados estatísticos. } \\
\text { Seria interessante para o aluno, complementar } \\
\text { essa atividade adaptando à sua realidade, ou } \\
\text { seja, pesquisar sobre as doses diárias de cada } \\
\text { tipo de alimento recomendado para a sua faixa } \\
\text { etária e comparar com os dados dessa pirâmide } \\
\text { alimentar. }\end{array}$ \\
\hline
\end{tabular}

Fonte: Elaborado pelos autores.

Assim sendo, o problema permite a formulação de perguntas estatísticas que podem ser respondidas com dados, e havendo elaboração e execução para a coleta, os dados são representados na Pirâmide Alimentar envolvendo a análise dos dados e a interpretação dos resultados está relacionada com todas as componentes anteriores.

Temos pelo menos duas situações a considerar nessa questão, primeiramente que os dados não foram coletados pelos alunos e a outra consideração está relacionada ao contexto de realidade do aluno. No entanto, até o presente momento, essa questão especificamente, é a que mais se aproxima de um problema elaborado utilizando a resolução de problemas, segundo o documento GAISE. Esse mesmo documento afirma que é preferível que os alunos realizem a coleta de dados, mas não é necessário em todos os casos.

Sugerimos a questão apresentada na Figura 6 que aborda conteúdos estatísticos utilizando a Resolução de Problemas segundo o GAISE. 
Os hábitos brasileiros podem ser apontados como responsáveis pela reformulação da pirâmide alimentar. Segundo dados da Pesquisa de Orçamento Familiar, do Instituto Brasileiro de Geografia e Estatística (IBGE), mostraram uma "epidemia" de excesso de peso, pois, entre 2006 e 2010 sendo que o número de homens com quilos a mais do recomendado passou de $18,5 \%$ para $50,1 \%$ e entre as mulheres, no mesmo período a proporção passou de $28,7 \%$ para $48 \%$.

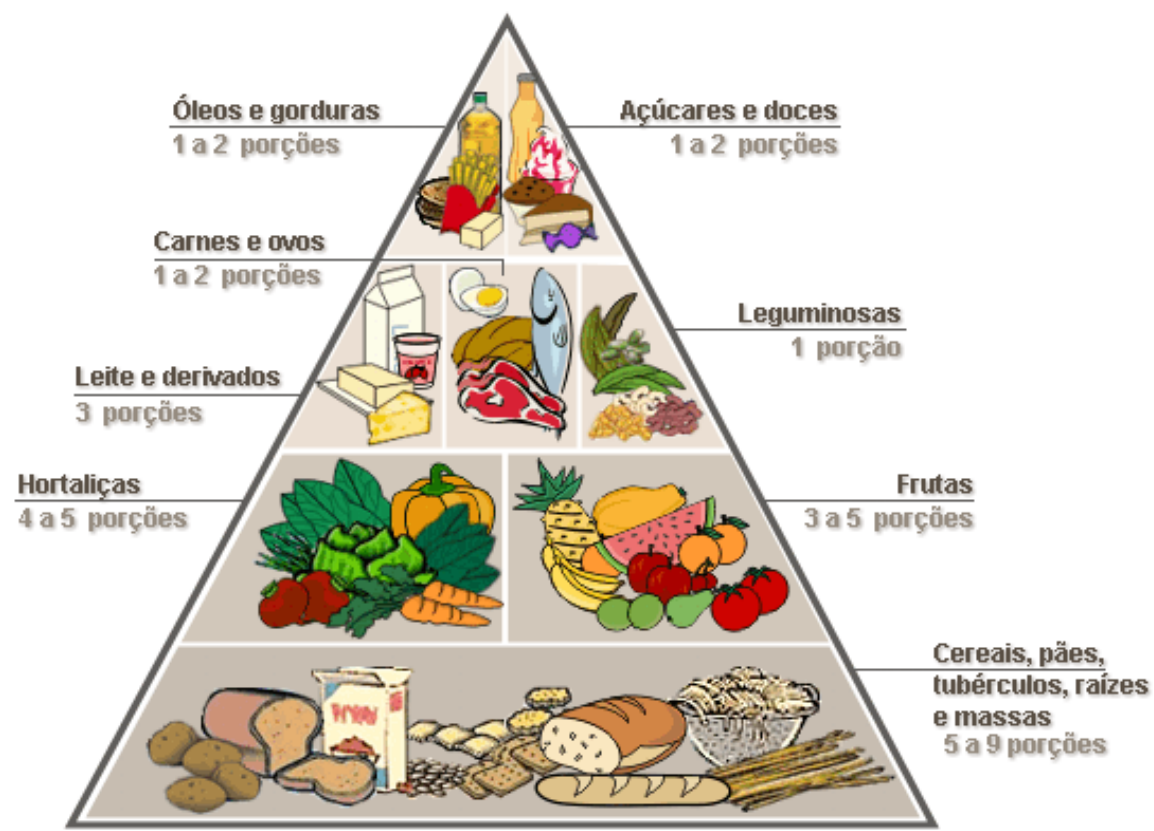

Fonte: Ministério da Saúde.

Figura 41 - Pirâmide Alimentar antiga.

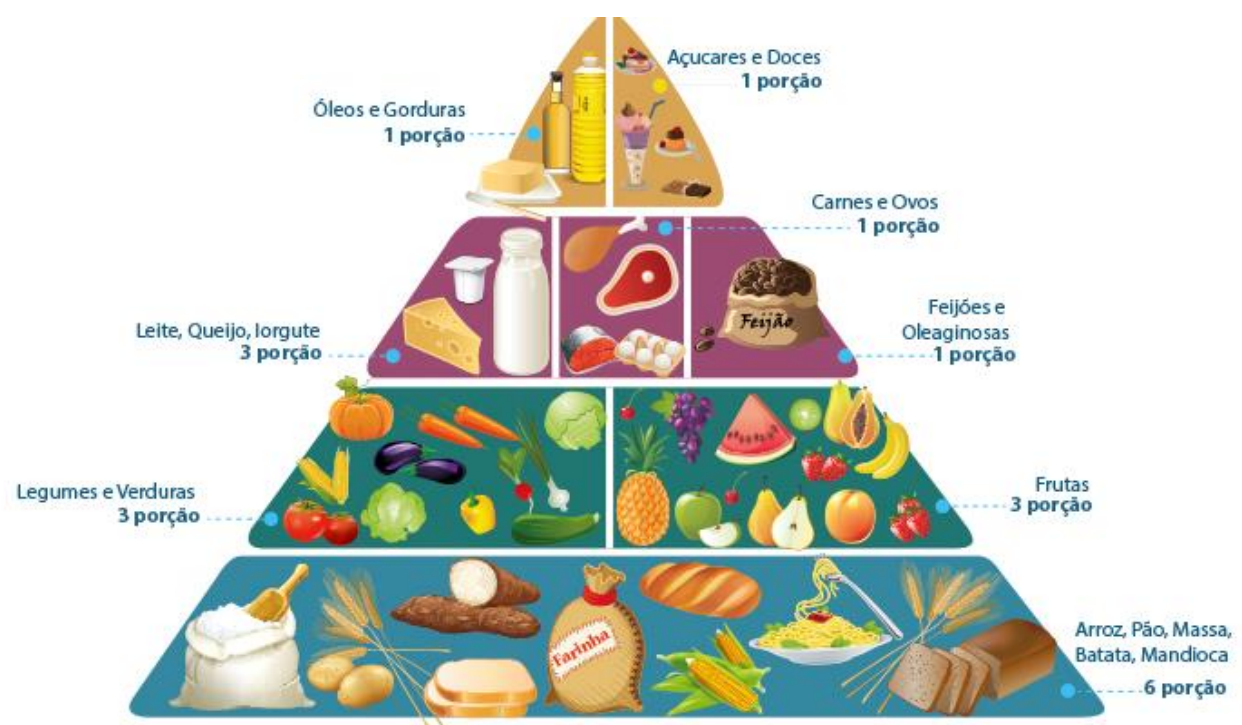

Fonte: Elaborado pelos autores.

Figura 6 - Sugestão de questão considerando o documento GAISE (resolução de problemas e variabilidade). 
Segundo SEE (2012), Relatório Pedagógico Saresp 2011, a Questão apresentada na Figura 7 pretende avaliar a seguinte habilidade: Resolver problemas que envolvam informações apresentadas em tabelas e/ou gráficos (H42).

Observe no gráfico o resultado de uma pesquisa realizada pela professora da escola "Saber é Bom" com os seus alunos.

Se cada criança escolheu apenas uma atividade preferida, quantas foram entrevistadas nessa pesquisa?
(A) 30
(B) 75
(C) 80
(D) 90

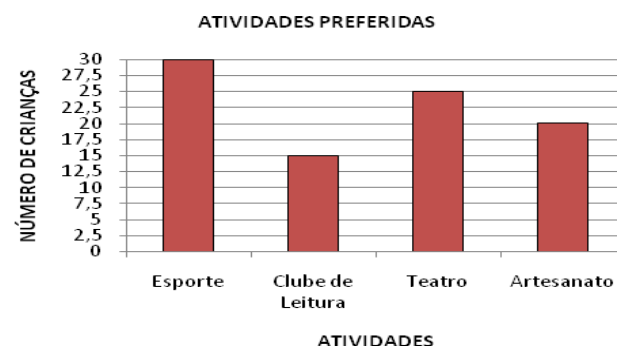

Fonte: SEE (2012, p. 142).

Figura 7 - Exemplo 2 de item da prova do Saresp 2011 para o $9^{\circ}$ ano do Ensino Fundamental.

Essa questão solicita habilidades interpretativas e alfabetização estatística, visto que é necessário associar informações apresentadas no gráfico. Para solucionar essa questão o estudante deve conseguir ler, entender e interpretar o enunciado se atentando que cada criança escolheu apenas uma atividade preferida. Observando o gráfico de colunas em análise, podese dizer que os dados são 30, 15, 25 e 20, alturas dos retângulos, e representam o número de alunos entrevistados para cada atividade. Assim sendo, basta somar $30+15+25+20=90$, assinalando a alternativa " $\mathrm{D}$ ".

O quadro 6 apresenta análise da questão apresentada na figura 7 referente à resolução de problemas segundo o documento GAISE focado nas quatro componentes do processo, bem como aos aspectos da variabilidade.

Quadro 6 - Análise do item referente ao ano de 2011 considerando o documento GAISE.

\begin{tabular}{|c|c|}
\hline Resolução de Problemas segundo o documento GAISE & $\begin{array}{c}\text { Resolução de Problemas e a Variabilidade } \\
\text { segundo o documento GAISE }\end{array}$ \\
\hline $\begin{array}{l}\text { 1) A pergunta inicialmente formulada poderia ser, por } \\
\text { exemplo, "Qual a sua atividade preferida fora da escola?". A } \\
\text { pergunta está relacionada à primeira componente do } \\
\text { processo investigativo da resolução de problemas "Formular } \\
\text { perguntas". No entanto, a pesquisa foi realizada pela } \\
\text { professora da escola, ou seja, os alunos foram os } \\
\text { entrevistados da pesquisa. } \\
\text { 2) A "Coleta de dados" a que se refere a segunda } \\
\text { componente foi realizada pela professora e os alunos } \\
\text { entrevistados forneceram os dados para o desenvolvimento } \\
\text { da pesquisa. A coleta de dados está contextualizada com a } \\
\text { realidade do aluno, apesar dele ser ele o entrevistado. } \\
\text { 3) A terceira componente "Análise dos dados" está } \\
\text { vinculada a pergunta inicial, a coleta de dados e se refere à } \\
\text { representação desses dados no gráfico de colunas. Observa- } \\
\text { se que o número de crianças intitulado no eixo vertical do } \\
\text { gráfico deveria ser representado somente por números } \\
\text { inteiros, pois a variável em questão é quantitativa discreta e }\end{array}$ & $\begin{array}{l}\text { Na questão, foi abordada a natureza da } \\
\text { variabilidade natural, visto que os alunos } \\
\text { pesquisados têm preferências diferentes em } \\
\text { relação a atividades que podem ser realizadas } \\
\text { fora da sala de aula como: praticar esportes; } \\
\text { participar de clube de leitura; ir ao teatro; ou } \\
\text { construir material de artesanato; dentre outras. } \\
\text { A pergunta inicialmente formulada "Qual a sua } \\
\text { atividade preferida fora da escola?" é uma } \\
\text { pergunta estatística que indica uma resposta } \\
\text { baseada em dados que podem variar. Há } \\
\text { diversos fatores que poderiam ser considerados } \\
\text { na questão, dentre eles o fato das categorias das } \\
\text { atividades serem criadas pela professora, } \\
\text { escolhidas pelos alunos ou foram somente } \\
\text { consideradas as quatro atividades mais votadas } \\
\text { em sala de aula, por exemplo. Nota-se que não } \\
\text { se pode afirmar como a questão foi apresentada }\end{array}$ \\
\hline
\end{tabular}


DOI: $10.20396 /$ zet.v28i0.8656898

deve ser representada por números inteiros.

4) A quarta componente "Interpretação dos resultados" está relacionada à pergunta inicial, à coleta e à análise dos dados, no entanto, somente nessa componente o aluno é envolvido no processo investigativo para solucionar a questão apesar de solicitar a o número total de participantes na pesquisa que a nosso ver não aproveita o potencial da questão.

Fonte: Elaborado pelos autores. para o aluno entrevistado.

Essa questão poderia se tornar desafiadora para o aluno se a pesquisa fosse realizada coletivamente em sala de aula. Observando os fatores que interferem no processo investigativo da resolução de problemas, e consequentemente, nas interpretações dos resultados.

Assim sendo, considera-se que essa questão não foi elaborada utilizando a resolução de problemas segundo o GAISE, pois somente, e parcialmente, na quarta componente os alunos foram envolvidos no processo investigativo. Segundo GAISE, a Educação Estatística deve ser vista como um processo de desenvolvimento, levando o aluno a refletir sobre os aspectos da coleta de dados, da análise e da pergunta na interpretação dos resultados.

Sugerimos a questão apresentada na Figura 8 que aborda conteúdos estatísticos utilizando a Resolução de Problemas segundo o GAISE.

Considere a Tabela 2 que apresenta os resultados obtidos em pesquisa que tinha como objetivo identificar o tipo de atividade de lazer preferida por alunos de uma turma do nono ano do Ensino Fundamental.

Tabela 2 - Distribuição dos tipos de atividades de lazer fora da sala de aula.

\begin{tabular}{c|c}
\hline Lazer & Número de aluno \\
\hline Praticar esportes & 16 \\
\hline Assistir Televisão & 7 \\
\hline Ir ao cinema & 6 \\
\hline Jogos eletrônicos & 4 \\
\hline
\end{tabular}

Elabore uma pesquisa que possa ser realizada em sala de aula para identificar os esportes preferidos por meninos e meninas em sua classe. Fonte: Elaborado pelos autores.

Figura 8 - Sugestão de questão considerando o documento GAISE (resolução de problemas e variabilidade).

Segundo SEE (2013), Relatório Pedagógico Saresp 2012, a Questão apresentada na Figura 9 pretende avaliar a seguinte habilidade: Resolver problemas que envolvam informações apresentadas em tabelas e/ou gráficos (H42).

A tabela a seguir mostra o resumo de quatro pesquisas de opinião antes das eleições.

\begin{tabular}{|c|c|}
\hline PESOUISA & RESULTADO \\
\hline 1 & Em cada 1.200 eleitores, 600 votarão no candidato A. \\
\hline 2 & $55 \%$ dos eleitores votarão em A. \\
\hline 3 & 1 em cada 2 eleitores votará em A. \\
\hline 4 & 2 em cada 10 eleitores votarão em A. \\
\hline
\end{tabular}

O resultado mais favorável ao candidato A foi o resultado da:

(A) pesquisa 1 .

(B) pesquisa 2 .

(C) pesquisa 3 .

(D) todas as pesquisas mostram o mesmo resultado.

Fonte: SEE (2013, p. 132).

Figura 9 - Exemplo 3 de item da prova do Saresp 2012 para o $9^{\circ}$ ano do Ensino Fundamental.

Essa questão solicita habilidades interpretativas e alfabetização estatística, visto que é preciso analisar os dados da tabela e estabelecer a probabilidade de cada afirmação. Assim, para solucionar o estudante deve comparar as afirmações feitas para escolher a maior delas. A alternativa correta é a letra "B". 
O quadro 7 apresenta análise da questão apresentada na figura 9 referente à resolução de problemas segundo o documento GAISE focado nas quatro componentes do processo, bem como aos aspectos da variabilidade.

Quadro 7 - Análise do item 3 referente ao ano de 2012 considerando o documento GAISE.

\begin{tabular}{|c|c|}
\hline Resolução de Problemas segundo o documento GAISE & $\begin{array}{c}\text { Resolução de Problemas e a Variabilidade } \\
\text { segundo o documento GAISE }\end{array}$ \\
\hline $\begin{array}{l}\text { 1) Nessa questão a pergunta formulada poderia ser, por } \\
\text { exemplo, "Qual o candidato em que votará?" envolvendo } \\
\text { a primeira componente do processo "Formular perguntas". } \\
\text { Observa-se que essa questão é estatística devido à } \\
\text { presença da variabilidade dos dados. O contexto não está } \\
\text { relacionado com a realidade do aluno e a pergunta inicial } \\
\text { não foi elaborada por ele. } \\
\text { 2) A segunda componente "Coleta de dados" está } \\
\text { envolvida na resolução do problema e vinculada a } \\
\text { pergunta inicial, entretanto a coleta de dados não foi } \\
\text { realizada pelo aluno, ou seja, os dados foram coletados } \\
\text { por outras pessoas. } \\
\text { 3) A "Análise dos dados" que envolve a terceira } \\
\text { componente está vinculada à pergunta inicial e à coleta. } \\
\text { Observa-se que os dados coletados estão representados na } \\
\text { tabela e que as quatro pesquisas realizadas apresentam } \\
\text { resultados somente para o candidato A. Esse fato está } \\
\text { descontextualizado da nossa realidade, pois geralmente os } \\
\text { candidatos têm pelo menos um concorrente e as pesquisas } \\
\text { aparecem de forma comparativa entre eles. } \\
\text { 4) A quarta componente "Interpretação dos resultados" } \\
\text { está vinculada à pergunta formulada, à coleta de dados e à } \\
\text { análise dos resultados. No entanto, somente na quarta } \\
\text { componente o aluno se envolve no processo investigativo } \\
\text { da resolucão de problema. }\end{array}$ & $\begin{array}{l}\text { Nessa questão não foi abordada a natureza da } \\
\text { variabilidade que poderia ser, por exemplo, de } \\
\text { amostragem, visto que a pesquisa foi realizada } \\
\text { com eleitores. } \\
\text { Nota-se que alguns fatores não foram } \\
\text { considerados nessas pesquisas, o que nos faz } \\
\text { refletir sobre as interpretações desses resultados, } \\
\text { por exemplo, as únicas opções de respostas para } \\
\text { essa pesquisa é sim ou não. } \\
\text { Será mesmo que todos os entrevistados } \\
\text { responderam somente sim ou não em relação ao } \\
\text { voto para o candidato A. E os candidatos que não } \\
\text { souberam, ou não opinaram? Observe que as } \\
\text { questões estatísticas há a variação de dados elas } \\
\text { interferem no resultado da pesquisa. A questão de } \\
\text { pesquisa poderia ser: "Qual o candidato em que } \\
\text { votará?" } \\
\text { Essa mesma questão seria interessante para ser } \\
\text { trabalhada em sala de aula com os alunos, para } \\
\text { refletirem sobre como essa pesquisa pode ter sido } \\
\text { conduzida. Se o fato de não apresentar outro } \\
\text { candidato na pesquisa tem algum significado para } \\
\text { a divulgação da pesquisa para a sociedade. Se não } \\
\text { considerarmos as outras possibilidades de } \\
\text { respostas, será que a pesquisa é confiável? }\end{array}$ \\
\hline
\end{tabular}

Fonte: Elaborado pelos autores.

Conclui-se que, essa questão não foi elaborada utilizando a resolução de problemas segundo o documento GAISE, pois não atende o processo investigativo das quatro componentes. Nota-se também a falta de contextualização no enunciado da questão, onde poderia estar expresso, por exemplo, alguma informação sobre as eleições, como as coletas de dados foram realizados, se havia outros concorrentes políticos, entre outros.

Sugerimos a questão apresentada na Figura 10 que aborda conteúdos estatísticos utilizando a Resolução de Problemas segundo o GAISE.

Em certa eleição municipal foram obtidos os seguintes resultados numa pesquisa eleitoral com 700 eleitores, Tabela 3:

Tabela 3 - Pesquisa eleitoral com 700 eleitores.

\begin{tabular}{|c|c|c|}
\hline Candidato & $\begin{array}{l}\text { Número de votos na pesquisa }(\mathrm{n}= \\
700)\end{array}$ & Porcentagem de intenção de votos \\
\hline $\mathrm{A}$ & $26 \%$ & 182 \\
\hline $\mathrm{B}$ & $24 \%$ & 168 \\
\hline $\mathrm{C}$ & $22 \%$ & 154 \\
\hline
\end{tabular}


DOI: $10.20396 /$ zet.v28i0.8656898

Nulo ou Branco $28 \%$ 196

Considerando que em outubro de 2016 serão realizadas eleições para prefeito e vereadores em seu município e sabendo que o município em questão tem três candidatos, A, B e C, disputando o cargo para prefeito, o que você sugere para determinar a evolução da intenção de votos dos eleitores e que se aproxime dos resultados obtidos na apuração dos votos em outubro?

Fonte: Elaborado pelos autores.

Figura 10 - Sugestão de questão considerando o documento GAISE (resolução de problemas e variabilidade).

Segundo SEE (2014), Relatório Pedagógico Saresp 2013, a Questão apresentada na Figura 11 pretende avaliar a seguinte habilidade: Associar informações, apresentadas em listas e/ou tabelas simples, aos gráficos que as representam e vice-versa (H43).

Com as promoções que muitas companhias aéreas têm feito, fica cada vez mais fácil viajar de avião. Observe no gráfico abaixo o aumento do número de passageiros nos últimos anos.

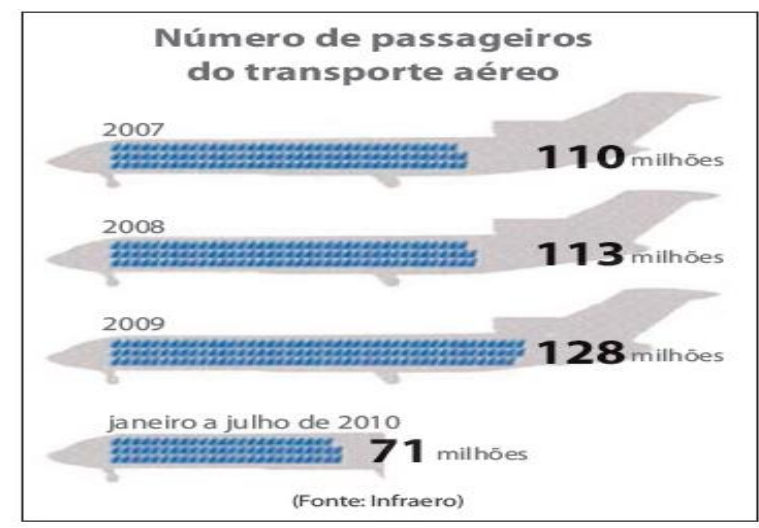

A tabela que melhor representa este gráfico é:

(A)

\begin{tabular}{c|c|c}
\hline Ano & Meses & $\begin{array}{c}\text { Número de Passageiros } \\
\text { (em milhões) }\end{array}$ \\
\hline 2007 & janeiro a dezembro & 71 \\
\hline 2008 & janeiro a dezembro & 128 \\
\hline 2009 & janeiro a dezembro & 113 \\
\hline 2010 & janeiro a julho & 110 \\
\hline
\end{tabular}

(C)

\begin{tabular}{c|c|c}
\hline Ano & Meses & $\begin{array}{c}\text { Número de Passageiros } \\
\text { (em milhões) }\end{array}$ \\
\hline 2007 & janeiro a dezembro & 110 \\
\hline 2008 & janeiro a dezembro & 113 \\
\hline 2009 & janeiro a dezembro & 71 \\
\hline 2010 & janeiro a julho & 128 \\
\hline
\end{tabular}

(B)

\begin{tabular}{c|c|c}
\hline Ano & Meses & $\begin{array}{c}\text { Número de Passageiros } \\
\text { (em milhões) }\end{array}$ \\
\hline 2007 & janeiro a dezembro & 113 \\
\hline 2008 & janeiro a dezembro & 110 \\
\hline 2009 & janeiro a dezembro & 71 \\
\hline 2010 & janeiro a julho & 128 \\
\hline
\end{tabular}

(D)

\begin{tabular}{c|c|c}
\hline Ano & Meses & $\begin{array}{c}\text { Número de Passageiros } \\
\text { (em milhões) }\end{array}$ \\
\hline 2007 & janeiro a dezembro & 110 \\
\hline 2008 & janeiro a dezembro & 113 \\
\hline 2009 & janeiro a dezembro & 128 \\
\hline 2010 & janeiro a julho & 71 \\
\hline
\end{tabular}

Fonte: SEE (2014, p. 113)

Figura 11 - Exemplo de item da prova do Saresp 2013 para o $9^{\circ}$ ano do Ensino Fundamental.

Essa questão solicita habilidades interpretativas e alfabetização estatística, para transposição de dados do gráfico para a tabela que o representa. Para solucionar essa questão o estudante deve relacionar o número de passageiros ao seu respectivo ano. A alternativa correta é a letra "D". 
O quadro 8 apresenta análise da questão apresentada na figura 11 referente à resolução de problemas segundo o documento GAISE focado nas quatro componentes do processo, bem como aos aspectos da variabilidade.

Quadro 8 - Análise do item referente ao ano de 2013 considerando o documento GAISE.

\begin{tabular}{|c|c|}
\hline Resolução de Problemas segundo o documento GAISE & $\begin{array}{c}\text { Resolução de Problemas e a Variabilidade } \\
\text { segundo o documento GAISE }\end{array}$ \\
\hline $\begin{array}{l}\text { 1) A pergunta formulada inicialmente poderia ser, por } \\
\text { exemplo, "Qual o número anual de passageiros do } \\
\text { transporte aéreo do ano de } 2007 \text { a julho de } 2010 \text { ?". Essa } \\
\text { pergunta envolve a primeira componente "Formular } \\
\text { perguntas" do processo investigativo da resolução de } \\
\text { problemas. No entanto, a pergunta não foi elaborada pelos } \\
\text { alunos e o contexto está não está relacionado à realidade } \\
\text { dele. } \\
\text { 2) A segunda componente "Coleta de dados" está vinculada } \\
\text { a pergunta inicial, no entanto, os dados não foram coletados } \\
\text { pelos alunos, ou seja, eles não foram envolvidos nesse } \\
\text { processo investigativo. No enunciado dessa questão, poderia } \\
\text { conter informações sobre como esses dados foram } \\
\text { coletados. } \\
\text { 3) A "Análise dos dados" envolve a terceira componente, } \\
\text { visto que os dados coletados estão representados no gráfico } \\
\text { pictórico utilizando como base um gráfico de barras. A } \\
\text { terceira componente está vinculada à pergunta inicial e à } \\
\text { coleta de dados. Entretanto, é somente nessa componente } \\
\text { que o aluno participa do processo investigativo em que tem } \\
\text { que associar os dados dispostos no gráfico com a tabela que } \\
\text { os representa. } \\
\text { 4) A quarta componente "Interpretação dos resultados" não } \\
\text { é considerada nessa questão, pois o aluno a resolve na } \\
\text { terceira componente. }\end{array}$ & $\begin{array}{l}\text { Nessa questão a natureza da variabilidade } \\
\text { abordada poderia ser a variabilidade de medição, } \\
\text { mas da forma que a questão está elaborada, não } \\
\text { se percebe indícios de variabilidade. O que } \\
\text { poderia ter sido considerado é que quando } \\
\text { existem as promoções percebe-se um aumento } \\
\text { do número de passageiros que podem estar } \\
\text { relacionados a proximidade de feriados } \\
\text { nacionais, por exemplo. } \\
\text { A formulação da pergunta estatística } \\
\text { "Qual o número anual de passageiros do } \\
\text { transporte aéreo do ano de } 2007 \text { a julho de } \\
\text { 2010?" Indica uma resposta baseada em dados } \\
\text { que variam, considerando diversos fatores que } \\
\text { podem interferir, como crise econômica, viagem } \\
\text { promocional, preço acessível, localização de } \\
\text { aeroportos, entre outros; considerando que a } \\
\text { interpretações devem ser realizadas à luz da } \\
\text { variabilidade. } \\
\text { Nessa questão seria interessante propor } \\
\text { uma pesquisa coletiva para os alunos sobre quais } \\
\text { as atividades preferidas desenvolvidas pelos } \\
\text { alunos fora da escola e no final fazer inferências } \\
\text { sobre a pesquisa realizada. }\end{array}$ \\
\hline
\end{tabular}

Fonte: Elaborado pelos autores.

Assim sendo, considera-se que essa questão não foi elaborada utilizando a resolução de problemas estatísticos segundo o documento GAISE, visto que os alunos não foram envolvidos no processo investigativo das componentes, além de a questão estar descontextualizada com a realidade dele.

Sugerimos a questão apresentada na Figura 12 que aborda conteúdos estatísticos utilizando a Resolução de Problemas segundo o GAISE.

A Tabela 4 mostra os voos que saem de três capitais da região Sudeste e da capital do País, bem como o percentual de variação (razão entre os voos extras e os voos regulares):

Tabela 4 - Número de voos que saem de três capitais da região Sudeste e da capital do País, bem como o percentual de variação.

\begin{tabular}{c|c|c|c|c}
\hline \multicolumn{5}{|c}{ percentual de variação. } \\
\hline Cidade-Sede & Voos Regulares & Voos Extras & Voos Totais & $\%$ Variação \\
\hline São Paulo & 20.261 & 6.401 & 26.662 & $31,6 \%$ \\
\hline
\end{tabular}


DOI: $10.20396 /$ zet.v28i0.8656898

\begin{tabular}{|c|c|c|c|c|}
\hline Rio de Janeiro & 5.977 & 2.678 & 8.656 & $44,8 \%$ \\
\hline Belo Horizonte & 6.931 & 789 & 7.721 & $11,4 \%$ \\
\hline Brasília & 3.392 & 2.175 & 5.567 & $64,1 \%$ \\
\hline
\end{tabular}
Fonte: Elaborado pelos autores.

Figura 12 - Sugestão de questão considerando o documento GAISE (resolução de problemas e variabilidade).

Segundo SEE (2018), Relatório Pedagógico Saresp 2018, a Questão apresentada na Figura 13 pretende avaliar a seguinte habilidade: Associar informações, apresentadas em listas e/ou tabelas simples, aos gráficos que as representam e vice-versa (H43).

O gráfico (Revista da Folha de São Paulo - 07.2011) mostra as menores temperaturas registradas a cada ano em São Paulo, de julho de 2000 a junho de 2011, e as datas em que elas foram anotadas.

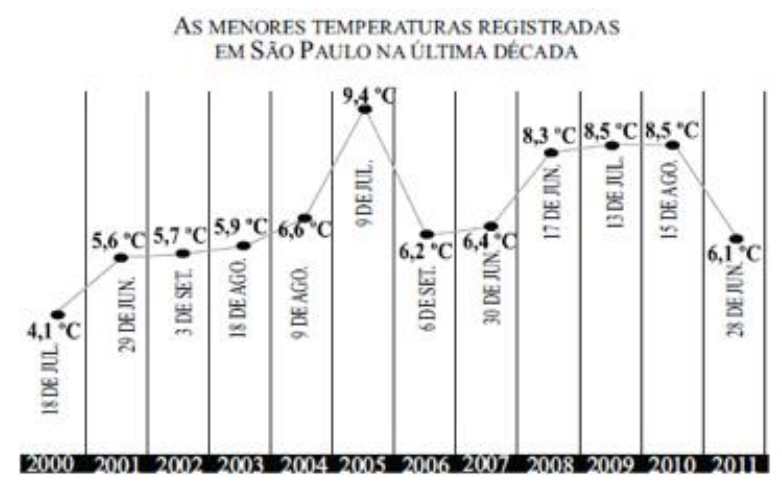

Fonte: Inmet - Instituto Nacional de Meteorologia.

De acordo com as informações do gráfico, é correto afirmar que:

(A) as menores temperaturas registradas a cada ano apresentam crescimento contínuo de 2000 a 2007.

(B) as menores temperaturas registradas a cada ano apresentam queda contínua de 2005 a 2008.

(C) as menores temperaturas registradas não foram iguais em nenhum ano desse período.

(D) a maior variação, em ${ }^{\circ} \mathrm{C}$, em relação à temperatura registrada no ano anterior, ocorreu em 2006.

Fonte: http://saresp.vunesp.com.br/resultados9mat.html.

Figura 13 - Exemplo de item da prova do Saresp 2017 e 2018 para o $9^{\circ}$ ano do Ensino Fundamental.

$\mathrm{O}$ item está associado à habilidade $\mathrm{H} 42$, descrita como "Resolver problemas que envolvam informações apresentadas em tabelas elou gráficos". O problema exige a leitura e análise dos dados presentes em um gráfico de linhas para identificar a afirmação correta, dentre quatro indicadas. Nesse caso, o gráfico exibido retrata a evolução das menores temperaturas registradas em São Paulo, no período de 2000 a 2011. A resposta correta é a letra (D).

O quadro 9 apresenta análise da questão apresentada na figura 13 referente à resolução de problemas segundo o documento GAISE focado nas quatro componentes do processo, bem como aos aspectos da variabilidade. 
Quadro 9 - Análise do item referente aos anos de 2017 e 2018 considerando o documento GAISE.

\section{Resolução de Problemas segundo o documento GAISE}

1) A pergunta formulada inicialmente poderia ser, por exemplo, "Quais foram as temperaturas mínimas em São Paulo no período de julho de 2000 a julho de 2001?". Essa pergunta envolve a primeira componente "Formular perguntas" do processo investigativo da resolução de problemas. Consideramos que a pergunta não foi deixado clara no enunciado, apesar de indicar que foi realizada coleta de dados.

2) A segunda componente "Coleta de dados" está vinculada a um problema inicial, no entanto, os dados não foram coletados pelos alunos, ou seja, não foram envolvidos nesses processo investigativo, mas foi embasada em dados obtidos em jornal de grande veiculação no estado de São Paulo. No enunciado dessa questão, poderia conter informações sobre como esses dados foram coletados.

3) A "Análise dos dados" envolve a terceira componente, visto que os dados coletados estão representados em um gráfico de linhas. A terceira componente está vinculada à uma questão inicial e que gerou, possivelmente uma coleta de dados há a participação do aluno, pois os dados foram retirados de um jornal, portanto, o aluno não participa do processo investigado em que tem que associar os dados dispostos no gráfico.

4) A quarta componente "Interpretação dos resultados" é considerada nessa questão, pois são realizadas afirmações que devem levar o aluno e fazer uma leitura e interpretação dos dados indicados no gráfico.

Fonte: Elaborado pelos autores.

Assim sendo, considera-se que essa questão foi elaborada utilizando parcialmente a resolução de problemas estatísticos segundo o documento GAISE, visto que os alunos não foram envolvidos no processo investigativo das componentes. No entanto, observamos que provoca o pensamento da variabilidade dos dados o que pouco vimos nas outras questões analisadas neste trabalho.

Sugerimos a questão apresentada na Figura 14 que aborda conteúdos estatísticos utilizando a Resolução de Problemas segundo o GAISE. 
Em uma sala de aula, uma professora solicitou aos alunos que realizassem uma pesquisa sobre as meno res temperaturas registradas em São Paulo de julho de 2000 a julho de 201,1colocando a seguinte questão de pesquisa Quais foram as temperaturas mínimas em São Paulo no período de julho de 2000 a julho de 2011 ? Um dos alunos realizando a pesquisa encontrou na Revista da Fo lha de São Paulo do mês de julho de 2011 o gráfico a seguir que apresentava a tendência da temperatura nesse período.

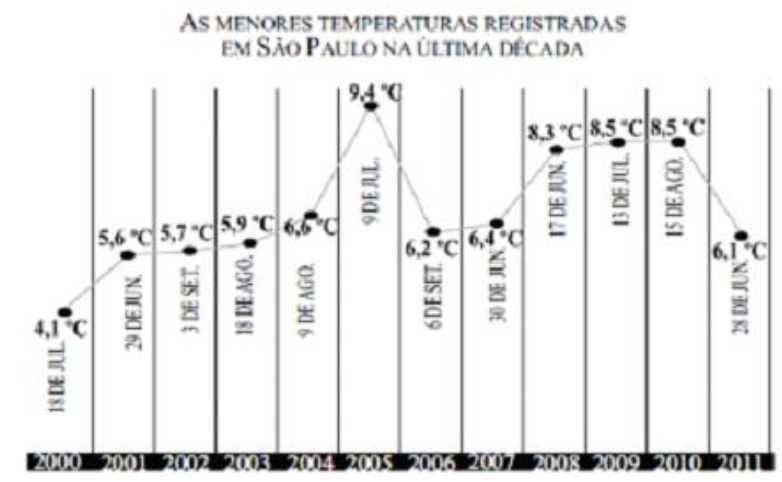

(Inmet - Instituto Nacional de Meteorologia)

De acordo com as informações observadas no gráfico veiculado na Revista é correto afirmar que:

(A) As menores temperaturas registradas a cada ano apresentaram crescimento contínuo de 2000 a 2007.

(B) As menores temperaturas registradas a cada ano apresentaram queda contínua de 2005 a 2008.

(C) As menores temperaturas registradas não foram iguais em nenhum ano desse período .

(D) A maior variação em ${ }^{\circ} \mathrm{C}$, em relação à temperatura registrada no ano anterior, ocorreu em 2006.

$$
\text { Fonte: Elaborado pelos autores. }
$$

Figura 14 - Sugestão de questão considerando o documento GAISE (resolução de problemas e variabilidade).

\section{Considerações Finais}

Consideramos que as questões analisadas nas provas do Saresp que abordam conteúdos estatísticos foram elaboradas utilizando parcialmente a resolução de problemas segundo o documento GAISE (Franklin et al., 2007) ao afirmar que a Educação Estatística deve ser vista como um processo de desenvolvimento, levando o aluno a refletir sobre os aspectos da coleta de dados, da análise e também da pergunta na interpretação dos resultados.

Essa afirmação se sustenta nas análises realizadas em que não há a preocupação em formular uma pergunta que norteie um processo de investigação e que compromete a coleta de dados ou informações a partir desta pergunta além de não indicar ser realizada pelos alunos e não abordar contexto próximo à realidade deste aluno ou ainda pior, não apresentar um contexto que dê suporte a posteriores representações, gráficas, tabulares ou de medidas estatísticas como a média e a mediana, e que por fim compromete intepretações vinculadas à pergunta inicial.

Apresentamos a seguir alguns aspectos que consideramos mais importantes e que fundamentam nossa afirmação de que as questões do Saresp se adequam parcialmente ao documento GAISE que apresenta a resolução de problemas vinculados a um processo investigativo e aos aspectos da variabilidade.

Vale destacar que propomos o agrupamento de questões com o intuito de evitar repetição de discussões ou conclusões. Outro fator considerado para o agrupamento das 
questões são as características convergentes a partir das análises realizadas em cada uma das questões do Saresp.

Assim, por exemplo, questões que envolvem informações apresentadas em tabelas e/ou gráficos estão relacionadas às questões apresentadas nas Figuras 7 (Saresp 2011) e 9 Saresp 2012). Consideramos que não são questões elaboradas utilizando a resolução de problemas estatísticos, segundo o GAISE. Nessas questões a componente referente à "Interpretação dos Dados ou Resultados" destaca-se por ser a única componente em que o aluno se envolve no processo investigativo, mesmo que não esteja relacionado à sua realidade.

Enfatizamos também a falta de contextualização nas questões do Saresp. Essa afirmação se sustenta nas análises realizadas em que a coleta de dados não foi realizada pelos alunos e o contexto das questões está distante da realidade dele. As questões indicam ao aluno se envolver em alguma parte de um processo investigativo, conforme as questões apresentadas nas Figuras 3 (Saresp 2009) e 11 (Saresp 2013). Quando o aluno é envolvido na componente "Análise dos Dados" solicita-se diretamente a solução da questão, mas não há nenhuma indicação para interpretação dos dados. A questão propõe simplesmente a associação de informações apresentadas em listas e/ou tabelas simples a gráficos que as representam e vice-versa, conforme os descritores do Saresp. Segundo GAISE, a Educação Estatística deve ser vista como um processo de desenvolvimento, levando o aluno a refletir sobre os aspectos da coleta de dados, da análise e da pergunta na interpretação dos resultados.

A questão apresentada na Figura 1 (Saresp 2008), que aborda a compra e o pagamento de um lanche, é problema matemático com pergunta determinística e não uma questão estatística que propõe a participação em um processo de investigação e muito menos fazer o aluno pensar que a variabilidade está presente neste processo. Considera-se que não foi elaborada utilizando o processo investigativo da resolução de problemas estatísticos segundo o documento GAISE, visto que para ser considerada com tal, é necessário que as quatro componentes do processo estejam envolvidas e ainda consideradas possíveis fontes de variabilidade.

A questão abordada na Figura 5 (Saresp 2010) é um problema que permite a formulação de uma pergunta estatística, pois pode ser respondida através dos dados. Portanto, é a questão que mais se aproxima do modelo apresentado no documento GAISE, juntamente com a questão apresentada na figura 13 (Saresp 2017 e 2018). No entanto, temos duas situações a considerar nessa questão: (1) Os dados não foram coletados pelos alunos; (2) Em relação ao contexto ou proximidade da realidade do aluno a pirâmide alimentar analisada poderia estar direcionada para a sua faixa etária.

$\mathrm{Na}$ questão (figura 5) foi abordada a variabilidade natural dos alimentos, pois com base em informações relacionadas a cada alimento eles foram agrupados e organizados na pirâmide alimentar, de modo que a análise e a interpretação dos resultados levem em consideração a variação das porções recomendadas diariamente para um adulto. 
Especificamente com relação à variabilidade foi abordada de maneira tímida nas questões do Saresp e não foi uma realidade facilmente observável. A questão 13 (Saresp 2017 e 2018) foi a única que consideramos que atende aos pressupostos da análise da variabilidade segundo o documento GAISE.

Foi desafiador a elaboração das questões, pois é necessário um estudo aprofundado sobre todas as abordagens expressas no documento GAISE. Primeiramente, é importante ter clareza da diferença entre uma pergunta que antecipa uma resposta determinística e uma pergunta que antecipa uma resposta baseada em dados que variam. A questão elaborada partiu da reflexão das questões analisadas nas provas do Saresp que poderiam ser aprimoradas para estar em consonância com a proposta de resolução de problemas do GAISE e suas abordagens de contexto, variabilidade, o aluno envolvido no processo investigativo.

A importância da elaboração dessas questões pode também servir de apoio a professores para trabalhar em sala de aula com seus alunos considerando fatores de adaptação, contexto, propostas, entre outros.

Dessa forma, o documento GAISE sugere o desenvolvimento conceitual em Estatística a partir do processo de resolução de problemas, levando em consideração o avanço nos níveis de desenvolvimento (formulação de um problema; coleta de dados; análise de dados; e interpretação de dados), por meio da conscientização quanto às ideias e aos conceitos envolvidos em uma investigação exploratória de dados. Semelhante desenvolvimento está intimamente relacionado à compreensão das naturezas da variabilidade presente no processo (natural; de medição; de amostragem; e induzida). Com a compreensão dos princípios estatísticos e de variabilidade, acreditamos no que é apresentado no documento GAISE, ou seja, tornar possível o desenvolvimento da postura crítica diante de informações que envolvam incerteza.

\section{Referências}

Chamorro, M. \& Vecino, F. (2003). El tratamiento y la resolución de problemas. En Chamorro, M. (Ed.), Didáctica de las Matemáticas para Primaria (pp. 273-299). Madrid: Pearson Educación.

Díaz, V. \& Poblete, A. (2001). Contextualizando tipos de problemas matemáticos en el aula. Números: Revista de Didáctica de las Matemáticas, 45, 33-41.

Díaz-Levicoy, D. \& Mayorga, A. (2014). La resolución de problemas como herramienta para la integración de contenidos matemáticos. Revista Investigaciones em Educación, 14(1), 25-42.

Fini, M. E. (2018). Leitura crítica: matemática na proposta da BNCC. Disponível em: http://basenacionalcomum.mec.gov.br/images/relatoriosanaliticos/Parecer_7_MA_Maria_Eliza_Fini.pdf

Franklin, C. A. \& Newborn, D. S. (2006). The Statistical Education of Grades Pre-k-12 Teachers. A shared responsibility. Thinking and Reasoning with Data and Chance, $68^{\text {th }}$ yearbook of the National Council of Teachers of Mathematics. 
Franklin, C. A., Kader, G., Mewborn, D., Moreno, J., Peck, R., Perry, M. \& Schaeffer, R. (2007). Guidelines for assessment and instruction in statistics education (GAISE) Report: A Pre-K-12 Curriculum Framework. Alexandria, VA. Disponível em: https://www.amstat.org/education/gaise/GAISEPreK-12.htm

Gal, I. (2002). Adult's statistical literacy: Meaning, components, responsibilities. International Statistical Review, 70(1), 1-25.

Garfield, J. \& Ben-Zvi, D. (2007). How Students Learn Statistics Revisited: A Current Review of Research on Teaching and Learning Statistics, International Statistical Review, 75(3), 372-396.

Groth, R. E. (2006). Engaging Students in Authentic Data Analysis. In G. F. Burril, \& P. C. Elliott (Eds.). National Council of Teachers of Mathematics Yearbook.

Herrera, A. (2013). Ambientes de aprendizajes para favorecer el desarrollo del pensamiento y lenguaje matemático: la aventura de pensar en clase de matemática. Revista IberoAmericana de Estudos Em Educação, 8(4), 1019-1029.

Lammoglia, B. (2013). O Saresp: visão da matemática escolar por atores da rede estadual de ensino. Anais do 11 Encontro Nacional de Educação Matemática. Curitiba (PR): Pontifícia Universidade Católica do Paraná. Retirado em 15 de março, 2020, de: http://sbem.iuri0094.hospedagemdesites.ws/anais/XIENEM/pdf/1940_1382_ID.pdf

Lopes, C. A. E. (2008). O ensino da Estatística e da probabilidade na Educação Básica e a formação dos professores. Caderno Cedes, 28(7), 57-73.

Lopes, C. A. E. (2011). A Estocástica no Currículo de Matemática e a Resolução de Problemas. Anais do 2 Seminário de Resolução de Problema - SERP. Rio Claro (SP): UNESP.

Lopes, C. A. E. (2013). Educação Estatística no curso de licenciatura em Matemática. Bolema, 27(47), 901-915.

Lopes, C. A. E. \& Carvalho, C. (2009). Literacia Estatística na Educação Básica. In A. Nacarato, \& C. A. E Lopes. Escritas e Leituras na Educação Matemática (pp. 77-92). Belo Horizonte: Autêntica.

Ministério da Educação (MEC). (2017). Base Nacional Comum Curricular: Educação é a base. Ministério da Educação, Brasília, dez. 2017. Disponível em: http://basenacionalcomuma.mec.gov.br/images/BNCC_20dez_site.pdf

Onuchic, L. R. \& Allevato, N. S. G. (2005). Novas reflexões sobre o ensino-aprendizagem de matemática através da resolução de problemas. In M. A. V. Bicudo, \& M. C. Borba, M. C. (Orgs.), Educação Matemática - pesquisa em movimento (pp. 213-231). São Paulo: Cortez. 
DOI: $10.20396 /$ zet.v28i0.8656898

Pino, J. \& Blanco, L. (2008). Análisis de los problemas de los libros de texto de Matemáticas para alumnos de 12 a 14 años de España y de Chile en relación con los contenidos de proporcionalidad. Publicaciones, 38, 63-88.

Rossman, A., Medina, E. \& Chance, B. (2006). A Post-Calculus Introduction to Statistics for Future Secondary Teachers. Proceedings of 7 International Conference on Teaching Statistics (ICOTS). International Statistical Institute, Voorburg, The Netherlands. Retirado em 15 de março, 2020, de: https://iaseweb.org/documents/papers/icots7/2E2_ROSS.pdf

Secretaria da Educação do Estado de São Paulo (SEE). (2009). Matrizes de referência para a avaliação Saresp: documento básico/Secretaria da Educação. v. 1. coordenação geral, Maria Inês Fini. - São Paulo: SEE.

Secretaria da Educação do Estado de São Paulo (SEE). (2009a). Relatório Pedagógico: Saresp 2008. Coordenação geral: Maria Inês Fini. São Paulo: SEE.

Secretaria da Educação do Estado de São Paulo (SEE). (2010). Relatório Pedagógico: Saresp 2009. Coordenação geral: Maria Inês Fini. São Paulo: SEE.

Secretaria da Educação do Estado de São Paulo (SEE). (2011). Relatório Pedagógico: Saresp 2010. Execução: Fundação Vunesp. São Paulo: SEE.

Secretaria da Educação do Estado de São Paulo (SEE). (2012). Relatório Pedagógico: Saresp 2011. Execução: Fundação Vunesp. São Paulo: SEE.

Secretaria da Educação do Estado de São Paulo (SEE). (2013). Relatório Pedagógico: Saresp 2012. Execução: Fundação Vunesp. São Paulo: SEE.

Secretaria da Educação do Estado de São Paulo (SEE). (2014). Relatório Pedagógico: Saresp 2013. Execução: Fundação Vunesp. São Paulo: SEE.

Secretaria da Educação do Estado de São Paulo (SEE). (2018). Relatório Pedagógico: Saresp 2018. Execução: Fundação Vunesp. São Paulo: SEE.

Snee, R. (1990). Statistical Thinking and its Contribution to Quality. The American Statistician, 44(2), 116-121.

Wallman, K. K. (1993). Enhancing statistical literacy: Enriching our society. Journal of the American Statistical Association, 88, 1-8. 